\title{
Impact of Wars and Conflicts on Women and Children in Middle East: Health, Psychological, Educational and Social Crisis
}

\author{
Yaser Snoubar
}

Nurdan Duman

\begin{abstract}
The wars and armed conflicts in many regions of the world and especially in the Middle East have an eloquent impact on all life's happenings most especially in areas affected. Wars destroys community infrastructure such as health, education and other social services sectors. As of present, the ongoing conflicts in the Middle East had left a significant impact on the family and the individual in the areas affected. In the family, it has lead to disintegration and roles change. It is also lead to forced migration and asylum. At the individual level, it have impacted negatively in terms of psychology, social and physical wellbeing. Women and children are the most affected by traumatic events of war and they are the most vulnerable to all types of exploitation and abuse. The devastating effects of war on this vulnerable group can hardly be overemphasized. This paper discusses the problems faced by children and women in war and conflict zones. It also explores physical, mental health, social and educational crisis experienced by women and children in the Middle Eastern society. A society that is known to have witnessed many civil wars and armed conflicts. In addition, the study also discusses social and health services which must be provided to women and children in conflict affected area from the social work perspective.
\end{abstract}

Keywords: wars and conflicts. Middle East Society, Health, psychological and social crises

\section{Why study children and women in war zone?}

Children and women category are more prone to all types of negligence and exploitation in warying enviroment and conflict. Undoubtedly, war provide an avenue for all such of exploitation when it arises. Most especially with regards to the middle East where countinuing conflicts has led to demolition of most aspect of life and has greatly affected all segments of society, disrupting health and educational service provision which form the backbone of life in many middle east countries.

Although, women played a large role in a society they still occupy the lowest echelones in the society, and this is most true in third world countries. Wars increase the pace of marginalization that can be mentioned at several points. There is need to examine a quick solutions by all humanity and international organizations to these crisis especially among the most prominent that is aganist women in times of war, these includes :

Forced to participate in acts of violence and armed conflicts

Exposure to killing, disability and prison

Poverty,malnutrition and deteriorating health situation

Displacement of women during war

Separation from the rest of the family and homelessness

Trafficking of women, sexual exploition and rape 
Asumming the role of the family due to lost of husband which forced them to work for very low salaries and vulnerable to different kinds of explotion.

"In this context, children during and after the events of war and conflict, remain open to all kinds of abuse and neglect especially, sexual abuse, trafficking and abduction of children. Children's living in war environment and refugee camps leads them to remain at risk of neglect and abuse as victims as well as being used as shields. Especially those who were kidnapped by occupation forces suffered sexual and physical abuse in prison. At this point, there are no any sanctions of international agreements and organizations responsible for protecting children who are in war environment, from exposed to neglect and abuse in the war environment. It is an important issue that attracts attention. This is due to the fact that existing laws are not operating sufficiently in practice, this means that children are neglected in war zones" (Snoubar \& Duman, 2015).

Altough there are alot of agreements aimed in cases to protect civilians in times of armed conflict, but there is aclear gap in the application and overlooked from interational institutions in this matter. Here we must focus on the situation of woman and children during and after armed conflicts and effective intervention and legal protection that is lacking in many of the Middle East Countries.

"The majority of the Middle East countries lack proper social policy for the protection of youth, children and womens, and it shows a lack of planning for the social, educational, and economic services. Despite the lack of such services, the NGOs have played an important role for years in providing social services for women, children and youth through youth centers and provision of anti-unemployment, awareness and organization programs. Therefore, it is necessary to draw a social policy designed to protect them by offering social services, organized in cooperation between civil domestic and international institutions operating within the Middle East, in the absence of the role of the state or government institutions that marginalized the women, children and youth" (Snoubar \& Hawal, 2015) .

\section{Health status of Women and child during war and conflict}

In general, wars and armed conflicts are consider the basic causes of ill health and increase the number of deaths among children and women. Since the collapse of facilities and health centers and the difficulty of delivering service and health care for the population, especially of women and children led to the aggravation and worsening health status significaulty. In times of war and conflicts woman faces many problems and health risks that negatively affect the mental and physical well being and health of her child pregnancy child birth and post natal stage and in the various stages of life. The armed conflicts and wars cause displacement of families and locals from places of conflict to neighboring countries as refugees or displaced persons to theirplaces beleived to be safer. During the displacement period women and children faced many risks which is psychological and physical harmful to their health, including direct injuries leading to disabilities resulting from repeated attacks, shoot and mines as well as physical and sexual abuse,also sometimes flee trip be accompanied by the risk of death. In addition to the walk long distances and for along time with lack of food, water and lack of access to care along with malnutrition and disease. The resulting lack of hygiene leads to deterioration of the general health situations of women and children. War is the main reason for the difficulty of delivering health services especially to women and children, Pregnancy, prenatal and childbirth women are in dire need of medical follow-up, medical examination, awareness of health and health care such as immunization for the prevention of diseases. The loss of basic needs leads to abortion, low birth weight and loss of the ability to generate milk to breastfeed her child, the spread of disease and increase number of deaths(Gasseer et al, 2004).

During displacement or after access to refuge camps or places believed to be safer, many women and children especially girls vulnerable to assaults and sexual exploition by rival groups or by working in some women peacekeeping missions have sex exchange for food or aids (http://www. mefacts. com).

Attacks and unwated sexual activities leave the psyhologicsl and socisl effects on the negative (shock,confusion, depression, anxiety and isolation) on women as well as to the child who has witnessed cases of rape and sexual violance for any member of his family, also from health side leads to the sperad of sexually transmitted diseases, unwanted pregnancy (Gasseer et al, 2004). 
"It has to be known that children who are living in war and conflict environment experience both psycho-social and serious health problems as a result of being witness to acts of violence. Some of these problems are listed as; disability as a result of serious injury, the loss of children's lives during surgical operation as a result of not being able to provide the drugs to injured children or prevention from accessing the drugs by the children and the lack of medical supplies. These children, who are living in unusual situations of war, experience Post-Traumatic Stress Disorder (PTSD) especially when the safe places such as schools, mosques, churches that they took refuge are attacked and transformed into dangerous places. Also, some health problems expected such as death, injury, disability, illness from lack of food and beverages, can occur frequently for children living in war and conflict environment" (Snoubar \& Duman, 2015).

\section{Psychological status of Women and child in the war and conflict}

"War and conflict situations need to be addressed as crises situations as a result of devastation caused by it in the psychosocial and environmental conditions. In these violent environments, people especially children, are faced with lose are compelled to confront a sense of losing that extends from their material goods they have, as well as their loved ones" (Snoubar \& Duman, 2015). Children and young people are highly vulnerable to the effects of war, for multiple reasons. For instance, children are in many ways dependent on adults for their survival needs, such as food and water, and child-parent separation is a real danger during situations of armed conflict. Children and young people are still developing physically and psychologically. Implications of war and conflict, such as trauma and physical injury, can thus have a very long-term effect on their development and growth into adulthood (Dupuy \& Peters, 2010).

"In war and conflict situation children have psychological reactions as a natural response to shock include; Nightmares, Sleep difficulties, Physical symptoms (headaches, stomach aches, bed wetting), Withdrawal, Elective mutism, Difficulty concentrating, Exaggerated fears/worries, Hypervigilance. With support from family, friends etc., most children will overcome most of these distressing reactions through the "natural" healing process of time. However, the more adversities children experience, the more likely it is that they will have difficulty overcoming these distressing reactions. A small percentage of children are likely to remain in difficulty in the longer term and may need more focused help" (http://www. acdi-cida. gc. ca).

But the continuation of the war and lack of safe enviroment and the continuous exposure to violence both direct and indirectly prevent full recovery of these psychological symptoms in children. In times of crisis the family which is the main supporter of the child is disorganised that leads to disappearance of psychosocial support services. In many cases women also are living in a state of tiredness and psychological fatigue which the child suffers as a primary source for it. In addition, exposure to trauma associated with the separation from family and children is one of the things that lead to psychological problems among women in the Middle East. Others are the arrest and subjected to displacement and rape,beside to the loss of afamily member.

\section{Education status of child in the war and conflict}

The ongoing wars and conflicts in the Middle East have exacerbated the problem and the destruction of educational institutions targeted by artillery fire in many countries this led to depriving millions of children and young people of their right to education (Snoubar\& Hawal, 2015).

In addition, to the severe shortage of schools and educational facilities depriving many children of their right to education had generally increased violence among children in school,which led to alot of psychological and social problems for children. Thre increase in violence in schools can be traced back to indirect violence via television or exposure to violence through attacks of armed militias on schiils and educational facilities. This is accompanied by lack of concentration inwardness and straying of the child or the tendency for hooliganism and aggressive (snoubar,2010).

In short, you can outline the effects of war and armed conflict on women and childrens on educational status in many Middle Eastern countries on several things including:

increased school dropout status. 
droput due to forced migration.

situation of aggression and violence among children in schools.

using students to participate in the speed of direct aggression and dropping out of schook because of disability or imprisonment.

Demolition of educational facilities by parties to the conflict or used as a place of safe the for families during conflict led to decrease in schools.

Non-availability of awareness centers and educational programes for women increase maternity death.

\section{Social status Crisis of Women and child in the war and conflict}

The continuity of conflicts in many countries of the Middle East had play an adverse affect to the individual, the community and society as a whole. Among the negative effects of war is subjecting children and women to a challenging roles in the family, such as hard labour for low wages as in palestine. Drug abuse among youth, rising of school violence, compulsory recourse family to destitution disruption. The ongoing wars and conflicts in the Middle East had a negative impact on cultural value, it eradicate culture and traditions in the society.

In a study of children who were arrested after participating in the ongoing conflicts have found that they feel that society perceives them as heroes and freedom fighters because they have experienced and survived detention (Baker \& Kevorkian: 1999, 939).

Women have been exposed to several abuse and insult like the children, such as arrests, imprisonment and ill treatment. Many women are arbitrary arrested and sentenced to prison for many years. These are all the result of war and conflicts in the middle east.

\section{Conclusion}

Wars and armed conflicts have left in the Middle East a lot of crises on all segments of society. But this study focused on the analysis of light and psychological health, social and education for women and children crises because they are the most affected group in that crises. Although there are a lot of international legal agreements that provide for the protection of civilians in times of war and armed conflicts but it remained a dead letter. It has led the international silence and the absence of law to the infrastructure of educational and health facilities and services and the displacement of the civilian population and targeted acts of violence, killings and demolition of captivity. This resulted in emergence of a lot of problems that were displayed at the top. To overcome this crisis and protect children and women in times of crisis there should be effective policies applicable by international participation of humanitarian disciplines and institutions specifically in protecting women and children in the camps and places of refuge that should be status considered safe environment. Provide psychosocial support for children and women stranded and displaced persons in the war environment and conflict through a dedicated team under the supervision of international institutions for peacekeeping. Intensify the psychological and physical rehabilitation programs for children and women who have been subjected to acts of direct violence.

\section{References}

[1] BAKER, Ahmad., Kevorkian, Nadera, 1999, Effects of political and military traumas on children: the palestinian case. Clinical Psychology Review, 19(8), 935-950.

[2] Dupuy, KE \& Peters, K. (2010) War and Children A Reference Handbook. Praeger Security International, Santa Barbara.

[3] Gasseer, N., Dresden, E., Keeney, G., Warrenn, N. (2004). Status of Women and Infant in

[4] Complex Humanitarian Emergencies. Journal of Midwifery \&Women's Health, 49;7-13. 
[5] Snoubar, Yaser \& Hawal, Hamed (2015) "Young Communities and the Impact of Wars and Conflicts on the Healthy Growth of Young People: Middle East as a Model Study, European Journal of Interdisciplinary Studies, $129-136$

[6] Snoubar, Yaser \& Duman, Nurdan (2015) Using Social Holistic Approach in Working with Children who are in the War Zone. Mediterranean Journal of Social Sciences MCSER Publishing, Rome-Italy, 231-237.

[7] Snoubar, Y. (2010) Social Work With Children Problems in War Zone (Palestine az an Example). Social Work, Social Workers Association Publication, Number 20, 13-17.

[8] http://www. acdi-cida. gc. ca/INET/IMAGES. NSF/LLUImages/Childprotection/\$file/E12. pdf (20. 04 . 2015).

[9] http://www. mefacts. com/cached. asp?x_id=10387 (20.04. 2015) 